\title{
CRIANÇA E ADOLESCENTE COM CÂNCER EM TEIXEIRA DE FREITAS: VICISSITUDES APÓS O TRATAMENTO ONCOLÓGICO
}

\author{
AUTOR: BEATRIZ RIHS MATOS TAVARES \\ CO-AUTOR: MURILO SOUSA RAMOS \\ CO-AUTOR/ORIENTADOR: MILENA DOREA DE ALMEIDA
}

Resumo: Durante o processo de adoecer e sobreviver, a criança e o adolescente passam a ser confrontados com os limites do seu corpo, as significações sobre a morte e a vida, as mudanças na família e as suas relações interpessoais. Frente à doença, cada reação é única e depende da singularidade de cada pessoa. Esta pesquisa objetivou investigar os sentidos e significados que crianças e adolescentes, fora de terapia oncológica há pelo menos 02 anos, têm da doença, de seu tratamento e das experiências de vida durante e após o adoecimento. Todos residentes de Teixeira de Freitas e na faixa etária entre 08 e 19 anos. Devido à situação pandêmica do COVID-19, o planejamento foi readequado. As entrevistas semi-dirigidas com o público-alvo desta pesquisa não foram possíveis e foi realizada uma pesquisa com metodologia de revisão integrativa de literatura, com o objetivo de investigar as perspectivas das pesquisas científicas brasileiras dos últimos 20 anos cujos sujeitos de estudo são os sobreviventes de cânceres infantojuvenis a fim de analisar as principais temáticas envolvidas. Foram feitas buscas a partir dos descritores "sobreviventes", "câncer", criança", "adolescente", com o operador booleano AND, nas plataformas Google Acadêmico, SciELO, Pubmed, Lilacs e BVS, de artigos indexados em revista, no idioma português, com pesquisas realizadas no Brasil e que abordem estudos com sobreviventes de câncer infantojuvenil. Foram excluídos artigos de revisão de literatura e de pesquisas que tenham como público-alvo atores que não apenas os sobreviventes. Foram selecionados 21 artigos para o banco de dados bibliográfico. Destes, 10 abordaram os efeitos tardios físicos, 6 os psicossociais e 4 os subjetivos. Sobre os dois últimos, estudos indicam que somente uma minoria dos sobreviventes percebe prejuízo em sua saúde em geral, sugerindo que, em relação aos aspectos da sobrevivência, a maioria deles é resiliente. Sobre os efeitos tardios subjetivos, as pesquisas analisam profundamente as vicissitudes dos sobreviventes desde o diagnóstico até o pós-tratamento, descrevem os impactos dos efeitos tardios na vida deles e as possibilidades de ressignificações nesse processo. Por fim, esta pesquisa discute a importância de conhecer, de forma interdisciplinar e multicêntrica, as repercussões orgânicas, psíquicas e sociais da sobrevivência ao câncer infantojuvenil, pois se percebe um aumento nas chances de cura e essa precisa ser com qualidade de vida.

Palavras-chave: Pediatria, Sobrevivente de câncer, Impacto Psicossocial, Subjetividade. 